\title{
Ensino de História: como a extensão universitária potencializa a formação profissional ${ }^{1}$ Education of History: how the university extension potentiates professional education
}

Érika Oliveira Amorim*

\section{Resumo}

$\mathrm{O}$ artigo apresenta as ações de um projeto de extensão universitária desenvolvido pela Universidade do Estado de Minas Gerais (UEMG), unidade Carangola, que visa a formação profissional de estudantes do curso de licenciatura em História bem como dos graduandos do curso de Turismo. As ações desse projeto consistem no oferecimento de oficinas temáticas sobre Patrimônio Histórico e Memória e a realização de visita guiada ao Museu e Arquivo Histórico de Carangola, que envolvem alunos do $9^{\circ}$ ano do Ensino Fundamental de uma escola da rede pública estadual. $\mathrm{O}$ viés interdisciplinar do projeto possibilita aos graduandos o contato com dois possíveis campos de atuação profissional: a escola e o museu. Além disso, desperta nos estudantes da rede pública estadual a atenção para a relevância do acervo arquivístico e histórico do Museu da cidade.

Palavras-chave: ensino de História; extensão universitária; museus.

\begin{abstract}
This paper presents the actions of a university extension project developed by the Universidade do Estado de Minas Gerais (UEMG), Carangola unit, which aims at History degree course students and students of the Tourism course. The actions of this project consist in providing thematic workshops on History and Memory Heritage and conducting guided tour on Carangola Museum and Historical Archives, involving students from the $9^{\text {th }}$ grade of elementary school. The interdisciplinary bias design enables graduate students contact with two possible professional fields of activity: the school and the museum. Moreover, it awakens in students of public schools the importance of archival and historical collection of the City Museum.
\end{abstract}

Keywords: History teaching; university extension; museum.

\footnotetext{
* Doutoranda em História Social das Relações Políticas na Universidade Federal do Espírito Santo (Ufes). Professora do Curso de História da Universidade do Estado de Minas Gerais (UEMG). Carangola, MG, Brasil. erikaoamorim@hotmail.com
} 
O presente artigo aborda experiências do Projeto de Extensão "A Universidade, o Museu e nós: memória e patrimônio nos caminhos da extensão", desenvolvido na Universidade do Estado de Minas Gerais (UEMG), Unidade Carangola, desde 2014. Tem como foco a promoção de visitas educativas a museu, especificamente, ao Museu e Arquivo Histórico e Geográfico Carangolense. A escolha dessa temática justifica-se pela possibilidade de experiência educativa e pela promoção de relações cognitivas dos alunos e cidadãos com seu passado e presente, interagindo, ao mesmo tempo, com o museu, a cidade, a comunidade, a escola e a universidade.

Objetiva dinamizar o acesso de estudantes do ensino fundamental ao Museu, incentivando o conhecimento e a valorização do patrimônio histórico e da cultural local. Ao mesmo tempo, proporciona formação profissional aos discentes dos cursos de História e Turismo, pois possibilita o contato direto com o acervo histórico e arquivístico, a experiência do ensino de História e a organização de visitas guiadas.

\section{A extensão e SEUS PRotagonistas}

Pensar a universidade como campo de atuação, formação profissional e construção de novos saberes é abrir possibilidades para o trabalho de extensão, aliado às outras duas concepções constitutivas da universidade: o ensino e o desenvolvimento da pesquisa acadêmica. As atividades de extensão universitária consistem no aprofundamento do papel das instituições educadoras e no comprometimento com a transformação social, aproximando a comunidade da produção científica desenvolvida naqueles espaços.

No Brasil, o conceito de extensão universitária viveu basicamente quatro momentos. Perpassou a concepção de transmissão vertical do conhecimento; a ação voluntária sociocomunitária (o voluntarismo); a ação sociocomunitária institucional e o momento "acadêmico institucional". A extensão praticada de forma vertical, segundo Freire (2006), desconhece a cultura e o saber popular e se apresenta como detentora de um saber absoluto. Tal modelo, ao desconhecer a cultura da população a quem se destina, torna-se antidialógico e manipulador.

O modelo de ação voluntária sociocomunitária (o voluntarismo) dá à extensão a natureza meramente político/ideológica, mas representa também 
o início de uma tomada de consciência da necessidade de mudanças na forma de atuação das Universidades, em sua relação com a sociedade. Contudo, Freire considera que esse modelo representa avanços quando passa a considerar a cultura e o saber locais. Esse autor avalia que a extensão enquanto ação sociocomunitária institucional representa normatização, pois há a institucionalização da extensão centrada na forma de oferta de cursos e a difusão do conhecimento. Assim, estabelece-se uma via de "mão única" de uma Universidade que sabe algo para uma comunidade que não sabe nada. Esse modelo extensionista é tomado por um caráter redentor e messiânico, como afirma Freire.

No entanto, a partir dos anos 1980 surge o momento da extensão chamado de "acadêmico institucional", quando as ideias de Paulo Freire passam a fundamentar os conceitos e práticas da Extensão Universitária no Brasil. Dessa maneira, a atuação extensionista passa a ser vista como processo educativo estabelecendo uma via de mão dupla entre universidade e comunidade na qual Ensino e Pesquisa se articulam de forma indissociável. Nesse processo, são sujeitos tanto os professores e estudantes quanto os destinatários das ações de extensão, envolvidos nos princípios que regem a extensão universitária brasileira, pautados no compartilhamento, no diálogo, na interação e na construção coletiva de saberes.

Amparada nessa concepção a atividade extensionista permite uma troca de saberes entre o popular e o acadêmico de forma democrática que se integra com a realidade social da comunidade. Foi seguindo o modelo acadêmico institucional que as ações do projeto de extensão, apresentado neste artigo, se nortearam. A relação entre a universidade e a comunidade na qual está inserida concebe uma dinâmica dialética na qual os estudantes dos cursos de graduação reconhecem o conhecimento dos alunos do ensino fundamental, tais saberes são apropriados e um novo saber é construído.

$\mathrm{O}$ desenvolvimento do projeto envolve diferentes atores. Atende alunos da E. E. João Belo de Oliveira oferecendo oficinas temáticas que abordam os conceitos de Patrimônio Histórico e Memória. Nessas oficinas os estudantes dos cursos de graduação desenvolvem habilidades no que se refere a preparação de aulas, que se materializam por meio das oficinas, e assim promovem a sensibilização dos alunos para participarem da visita orientada ao Museu. 
Desde 2014, quando o projeto foi iniciado, oito graduandos participaram diretamente das ações. No primeiro ano, eram três estudantes voluntários, não recebendo nenhum tipo de bolsa ou auxílio de agências de fomento. A partir de 2015 o projeto passou a contar com um aluno bolsista, sempre auxiliado por um graduando voluntário. As ações - reuniões, grupos de estudo e preparação dos encontros - são realizadas no contraturno, nas dependências da UEMG, em Carangola. A professora coordenadora do projeto leciona no curso de História oferecendo as disciplinas Orientação de Estágio I, II e III, o que facilita o diálogo entre o projeto de extensão e o componente curricular obrigatório do curso de licenciatura em História. Os alunos que participam como bolsistas ou voluntários compartilham suas vivências no cotidiano da sala de aula com seus colegas da graduação em rodas de conversa desenvolvidas durante aulas daquelas disciplinas. As experiências também são apresentadas e debatidas em encontros acadêmicos promovidos anualmente pela UEMG, como por exemplo os Seminários de Pesquisa e Extensão. Nessas oportunidades, os estudantes demonstram o trabalho que desenvolvem, tendo em vista que em tais eventos o contato com a comunidade acadêmica permite um diálogo interdisciplinar e o intercâmbio de saberes com áreas afins, como Geografia - um dos outros cursos de licenciatura oferecidos pela UEMG em Carangola.

Outros atores sociais também são envolvidos durante a execução das ações extensionistas. O poder público atua na disponibilização do transporte para deslocamento dos alunos da escola ao museu. O supervisor escolar adapta as datas das oficinas ao planejamento pedagógico da instituição e o gestor escolar se responsabiliza pela autorização para sua realização, bem como pela saída dos estudantes do recinto da escola para o museu. A Universidade se constitui em agente quando, por intermédio do Núcleo de Extensão, aprova as ações do projeto e incentiva cada etapa. O desenvolvimento do trabalho é coordenado pela professora do Curso de História, a qual supervisiona a atuação dos graduandos que se envolvem cumprindo o cronograma estabelecido e vivenciam o papel de extensionistas. Os estudantes da rede pública estadual também são protagonistas do projeto, tendo em vista que compõem o processo de construção do conhecimento advindo das ações extensionistas. 
Dessa forma, o trabalho realizado no projeto provoca o protagonismo de todos, seguindo o que Gadotti (2006) aponta como pressuposto para que uma cidade seja considerada educadora:

a comunidade educadora reconquista a escola no novo espaço cultural da cidade, integrando-a a esse espaço, considerando suas ruas e praças, árvores, bibliotecas, seus pássaros, cinemas, bens e serviços, bares e restaurantes, teatros, suas igrejas, empresas e lojas... enfim, toda a vida que pulsa na cidade. A escola deixa de ser um lugar abstrato para inserir-se definitivamente na vida da cidade e ganhar, com isso, nova vida. Ela se transforma num novo território de construção da cidadania. (Gadotti, 2006, p.135)

A extensão universitária representa um processo acadêmico vinculado à formação cidadã tendo em vista que possibilita o intercâmbio de saberes. Articula o ensino e a pesquisa de maneira indissociável por meio do trabalho interdisciplinar. Especificamente, esse projeto trabalhado na UEMG envolve os cursos de História e Turismo, permitindo diálogos entre as duas formações. Procura-se conscientizar os graduandos para que tanto os profissionais da História como os do Turismo assumam o desafio do pensamento crítico e da sensibilidade para lidar com os espaços de memória e tudo o que representam para a sociedade.

A formação profissional dos graduandos da UEMG por meio das atividades extensionistas está relacionada ao desenvolvimento da prática pedagógica na perspectiva de contribuir para o acesso da comunidade aos bens culturais e patrimoniais que a cidade oferece, valorizando os saberes dessa população no processo coletivo de construção do conhecimento.

A extensão universitária desenvolve atividades que permitem a decisiva interligação entre a cultura científica e a cultura das humanidades, que é o papel dos museus, espaços expositivos, teatros, galerias, bibliotecas, arquivos e centros de documentação, veículos indispensáveis de mediação entre os produtores de conhecimentos e bens simbólicos e os destinatários dessas ações, sejam eles estudantes ou sujeitos externos à universidade, igualmente legítimos destinatários da ação universitária (Paula, 2013).

A vivência da extensão universitária por meio do projeto tem permitido que os acadêmicos vislumbrem e vivenciem seus possíveis campos de atuação profissional: a escola e o museu. Ademais, tem-se observado, na prática, a via 
de mão dupla da extensão haja vista que o conhecimento desenvolvido academicamente no espaço da universidade é compartilhado com os estudantes da rede pública estadual, atores de todo o processo extensionista.

\section{A UNIVERSIDADE, A ESCOLA E O MUSEU}

Segundo Pierre Nora (1993) os lugares de memória surgiram nas sociedades ocidentais modernas como esforço de construção de uma memória em desaparecimento. Já nas sociedades tradicionais, afirma o historiador francês, a memória está disseminada no tecido social e não é necessário guardar objetos ou fazer registros de qualquer ordem. No Brasil, a inserção da temática sobre Memória e Patrimônio Histórico e Artístico Nacional entra na pauta das elites políticas e intelectuais no início do século XX. Até então, as elites estavam mais preocupadas com a modernização das cidades do que com a recuperação de fragmentos do passado (Abreu, 2007, p.268).

Seguindo a proposta de preservar objetos históricos, foi criado em 1950 o "Museu e Arquivo Histórico de Carangola" instituído por meio de Lei Municipal de 14 de maio de 1959. Esse espaço possui considerável acervo de documentos históricos, fotografias, mobiliário, artes sacras, obras de arte produzidas por artistas locais e artefatos de tribos indígenas que viveram na região, bem como achados arqueológicos. Está sob a tutela da Secretaria Municipal de Cultura e, desde 2005, localizado em um antigo galpão construído em 1919, cedido em comodato pela Empresa Barbosa \& Marques à Prefeitura Municipal de Carangola por um período de 20 anos. Atualmente, o espaço físico é precário, apresentando problemas de infiltrações que comprometem o acervo.

Ao elaborar o projeto de extensão tratado neste artigo buscou-se valorizar o lugar de memória existente na cidade, já que Carangola se destaca pelo seu patrimônio histórico material e imaterial. Pensou-se ainda em transformar o espaço do museu em local de pesquisa e prática extensionista, em parceria entre a UEMG e a Prefeitura Municipal, entidade pública responsável por mantê-lo. Uma das potencialidades do projeto, além do trabalho interdisciplinar entre os cursos de graduação em História e Turismo da UEMG, consiste em destacar a necessidade de preservar o patrimônio histórico local e regional, bem como na emergência da manutenção e reforma do espaço físico que abriga o museu. Ademais, com objetivo de formar profissionais que atuarão no segmento 
educacional e possibilitar reflexões no tocante ao Ensino de História, as ações do projeto estão direcionadas à noção de cultura escolar. Nesse sentido, os graduandos são levados a compreender que o espaço escolar promove o cruzamento de sujeitos e saberes múltiplos e plurais (Gimeno Sacristán, 2000).

Na acepção de Antonio Viñao Frago (1998), cultura escolar engloba tudo o que acontece no interior da escola: as diferentes manifestações das práticas, normas e teorias que envolvem alunos e professores. O contato com a cultura escolar é estimulado pelo projeto de extensão, uma vez que o percurso da formação acadêmica de professores de História envolve a proximidade com o "chão" da sala de aula, bem como toda estrutura pedagógica que cinge.

A escola enquanto lócus de interação de múltiplos sujeitos se mostra um espaço legítimo para a promoção da consciência histórica, que perpassa o saber disciplinar e curricular. O espaço do museu e o contato dos graduandos dos cursos de Turismo e História em consonância com os estudantes da rede pública estadual visa demonstrar, na prática, o diálogo interdisciplinar.

A educação em museus visa à preservação do patrimônio cultural e natural, com a participação crítica de toda a população. Nesse sentido considerou-se a Educação Patrimonial como metodologia de ação educativa tendo em vista que alguns museus brasileiros vêm utilizando-a há décadas (Almeida, 1997).

O Instituto do Patrimônio Histórico e Artístico Nacional (Iphan) concebe educação patrimonial como: "todos os processos educativos que primem pela construção coletiva do conhecimento, pela dialogicidade entre os agentes sociais e pela participação efetiva das comunidades detentoras das referências culturais onde convivem noções de patrimônio cultural diversas". ${ }^{2}$

Grunberg (2000) define Educação Patrimonial como ensino centrado nos bens culturais, com metodologia que toma esses bens como ponto de partida para desenvolver a tarefa pedagógica. Dessa perspectiva o museu é colocado como parte da vida comunitária e local onde se preserva a memória (Alencar, 1987).

Segundo Almeida (1997) a proposta de Educação Patrimonial prevê a percepção/observação, motivação, memória e emoção, processo desenvolvido em três etapas: identificação do bem cultural (observação e análise); registro do bem cultural (atividades de registro da identificação) e valorização (interpretação e comunicação do observado e registrado).

De maneira a contemplar as três etapas propostas pela metodologia da Educação Patrimonial, o projeto de Extensão busca, primeiramente, discutir 
com os alunos os conceitos de memória e patrimônio. Há que se destacar que a discussão que abrange o conceito de memória, nesse projeto, está ancorada na concepção de Lopes (2016), que a considera como o modo pelo qual as culturas fazem relações entre passado, presente e futuro. Para esse mesmo autor, a "memória", assim como a "etnia" e a "identidade" são palavras de ordem nos tempos atuais e, por isso, o ensino de História deve tratar os "lugares de memória" no sentido crítico.

Esse momento de discussão e aproximação com a teoria ocorre durante a realização das oficinas e tem como objetivo preparar os estudantes para a observação e análise dos bens culturais encontrados no museu. Além disso, objetiva criar uma atmosfera de aproximação entre os alunos e os graduandos, que desenvolvem as atividades de extensão.

$\mathrm{Na}$ ocasião da visita os discentes realizaram observações e elaboraram questionamentos ao terem contato com os objetos expostos. Isso porque atualmente, o papel educativo dos museus suscita a reflexão crítica em vez da celebração (Lopes, 2016). Segundo esse autor, o museu coloca-se, agora, como o lugar onde os objetos são expostos para compor um discurso crítico e é por isso que a visita ao museu deve começar na sala de aula, com atividades lúdicas que utilizem materiais do cotidiano, como indícios de práticas que se fazem nas relações sociais (Lopes, 2016, p.3).

O museu, na contemporaneidade, assume-se como elemento inclusivo e reflexivo, diverso da concepção iluminista que acreditava ser possível, por meio de seu acervo, dispor de um conhecimento totalizante do mundo (Tavares, 2014). Assim, o museu nos dias atuais se coloca como ferramenta de construção de redes de conhecimento, com o olhar voltado aos eventos do cotidiano e as relações do cidadão com sua comunidade e, consequentemente, com o mundo.

A preparação das oficinas desenvolvidas pelo Projeto de Extensão levou em conta o perfil das novas gerações, tendo em vista que as percepções dos jovens do século XXI são diversas das concepções da juventude dos séculos anteriores. Hoje, o dinamismo das telecomunicações faz emergir o sentimento de imediatismo e de busca constante por tecnologia. Em um espaço como o Museu de Carangola, que não oferece ferramentas tecnológicas, outras possibilidades podem ser exploradas, aguçando o pensamento crítico sobre pequenas ações cotidianas. A exploração de objetos expostos como estimuladores da memória 
promove a oportunidade do diálogo entre memória e identidade. Os alunos compreendem assim que são agentes da história, construída cotidianamente.

Candau (2014) afirma que a memória está indissoluvelmente ligada à identidade das pessoas e é responsável por fortalecer o sentimento de identidade, tanto individual quanto coletivo.

A educação patrimonial pode exercer papel decisivo no processo de afirmação de identidades para que, como afirma Freire (2011), as pessoas se assumam como seres sociais e históricos, como seres pensantes, transformadores, realizadores de sonhos. Segundo a concepção freireana de compreender a cultura como mediação, ou seja, como forma de contribuir para a conscientização dos homens sobre seu papel de sujeito, cria-se uma educação libertadora. Nesse sentido, a educação patrimonial possibilita a construção de uma nova relação entre a população e seu patrimônio cultural.

Há que se levar em conta que, segundo pressupostos de uma educação emancipatória, o questionamento sobre os diversos tipos de patrimônios existentes, sobretudo no Brasil, é tarefa da Educação Patrimonial. Portanto, é fundamental considerar o patrimônio no contexto dos processos sociais em que foram produzidos superando uma visão acrítica, ou seja, evitando fetichizar ${ }^{3}$ (Scifoni, 2012) o patrimônio.

Ao visitar o museu, os estudantes exercem o que Siman, Pereira e Costa (2007) nomeiam por "função migratória". Nesse sentido, a visita é feita de desenraizamentos e o museu é considerado como um lugar de passagem, cuja finalidade é o percurso, não a chegada. Por esse percurso o desafio de aprender história é compartilhado por diferentes interrogações sobre o passado, o presente e o futuro.

O trabalho educativo no museu pode ser visto como oportunidade de possibilitar a interação entre professores e alunos e a construção de problematizações históricas. No momento atual, como afirma Siman (2003), tanto a cultura escolar quanto a cultura museológica encontram-se em processo de transformação, e novas práticas baseadas em novas concepções do que seja o ato de ensinar e aprender vêm contribuindo para a redefinição do papel da escola e do museu.

Os museus são espaços simbólicos, locais de observação, interação e reflexão. Enquanto espaços de educação não-formal oferecem possibilidades de aprendizagem diferentes das que acontecem nas salas de aula. Trata-se de um 
tipo de educação mais participativo e descentralizador, pois o aprendiz é motivado por suas percepções e motivações pessoais. O que cada visitante vai apreender é diferente do que o outro apreendeu, e o mais importante é instigar essa troca de diferentes olhares e observações, em momentos posteriores à visitação.

Para Francisco Régis Lopes (2016b), se há o pressuposto do museu como espaço de reflexão, é preciso construir um lugar de história. Assim:

se um museu pretende ser educativo, necessariamente deve existir o cultivo da crítica historicamente fundamentada. Afinal, não se trata apenas de promover o reconhecimento, mas o próprio conhecimento, que incomoda na medida em que conhecer não é confirmar o que se sabe. (Lopes, 2016b, p.94)

Esse estímulo é buscado pelos graduandos quando retornam à sala de aula e se utilizam de estratégias para que os estudantes participem desse momento de reflexões. Nesse liame a escola é uma mediadora do processo de formação dos jovens da rede pública estadual e dos graduandos da universidade, e a ferramenta fundamental para isso é a extensão. A interação entre comunidade e universidade, consequência imediata do trabalho extensionista, faz que a escola seja palco de um amálgama de saberes.

\section{FORMAÇÃO DOCENTE E ENSINO PARA ALÉM DOS MUROS DA ESCOLA}

Um dos desafios do processo de formação de professores de História é conscientizar os licenciandos quanto à construção do saber histórico. É levá-los a reconhecer que o sujeito que se encontra no espaço escolar é dotado de saberes, valores e memórias, e que o professor é um agente de transformação desses diferentes conhecimentos. Essa ação de agregar conhecimentos aos saberes que os estudantes já trazem consigo consiste numa dialética de significações e ressignificações produzidas em meio às interações. Tais interações podem ser desenvolvidas em diferentes espaços de aprendizagem, além da sala de aula. Aproximar o aluno de espaços culturais como o museu é explorar diferentes linguagens e ferramentas de aprendizagem. Estimular ao jovem estudante de licenciatura em História o contato com essa potencial ferramenta de trabalho também é desafiador. 
As potencialidades do ensino de História por meio da vivência em espaços museológicos são notórias. Contudo, como colocá-las em prática? Como mostrar ao jovem que se prepara para ser professor que levar seus alunos ao museu não significa trazer para si uma grande preocupação? Siman (2003, p.186) diz que o ato da visita a um museu por vezes é pautada na "pedagogia do não": não correr, não brincar, não conversar com os colegas. Sendo assim, de que maneira usufruir da visitação sem se pautar em práticas tradicionais do processo ensino-aprendizagem, como ouvir, fazer silêncio, anotar, copiar? Aproximar os discentes do curso de História da escola e de espaços culturais como o museu permite questionar perspectivas utilitaristas do ensino. É um momento no qual ocorre mútuo processo de aprendizagem entre professor, licenciandos e alunos. Sujeitos e objetos interagem. Em alguns momentos, os alunos podem parecer indiferentes, buscando compreender o significado dos objetos, mas logo se percebem conversas entre colegas e nesse momento o conhecimento está se construindo coletivamente.

Siman (2003, p.189) afirma que:

as visitas têm a característica de serem altamente sociais e que a aprendizagem se dá muito mais pela interação entre os indivíduos do que desses com a exposição. Das interações dos visitantes com o ambiente e destes entre si surgem perguntas relevantes, que suscitam discussões em grupos gerando a aprendizagem nesses locais.

A exploração da visitação ao museu vai além desse espaço. Muito do que se construiu e observou durante a visita vai ser sistematizado posteriormente em sala de aula, daí a relevância dos dois espaços para a construção do saber histórico. A escola será o espaço no qual o diálogo sobre o que se apreendeu da visitação é sistematizado. Consistirá no momento em que o aluno perceberá as observações que outros colegas fizeram sobre os mesmos objetos que conheceram, permitindo infinitas percepções. O projeto de Extensão aqui apresentado busca permitir que os estudantes de graduação desenvolvam esses tipos de ações e, ainda, tenham contato com o cotidiano escolar a fim de despertar sua percepção como autores, inventores e reinventores de sua prática.

Neste projeto, o trabalho de formação de professores tende a enfocar a prática docente considerando que o processo ensino-aprendizagem pode se dar em espaços que extrapolam o chão da sala de aula. O projeto trabalha com 
os futuros professores e turismólogos a noção de cidade educadora, no sentido de perceberem que:

a cidade precisa ser compreendida como território vivo, permanentemente concebido, reconhecido e produzido pelos sujeitos que a habitam. É preciso associar a escola ao conceito de cidade educadora, pois a cidade, no seu conjunto, oferecerá intencionalmente às novas gerações experiências contínuas e significativas em todas as esferas e temas da vida. (Moll, 2009, p.15)

Usufruir dos espaços da cidade e seus potenciais educadores possibilita ressignificar locais e monumentos que fazem parte do cotidiano dos cidadãos e que, muitas vezes, passam despercebidos de olhares e análises críticas. Despertando a criticidade por esses lugares, como o museu, praças e edifícios permite-se o enfoque que vai além do patrimônio como pedra e cal, e amplia-se a abordagem para as relações entre espaço e memória.

Bosi (1987) alerta que as "pedras da cidade" possuem elementos estruturantes e evocadores de memória que propiciam o estabelecimento de uma relação de continuidade entre passado e presente. Para essa autora, as lembranças apoiam-se nas pedras da cidade por meio de uma comunicação silenciosa (Bosi, 1987, p.361).

Assim, cidade, professores e alunos dialogam entre si construindo saberes e reconstruindo e reinterpretando lembranças, com suporte na memória. Oportunizar essa experiência prática tem sido uma das estratégias do projeto visando a formação de professores e turismólogos que agreguem a construção coletiva de memórias sobre o espaço da cidade.

A interdisciplinaridade do projeto se faz presente também ao oferecer aos graduandos a possibilidade de, antes de organizar a visita ao museu de Carangola, discutir a elaboração de planos de aulas que integrem abordagens históricas e o diálogo com outras disciplinas, como Literatura e Geografia.

É por isso que as oficinas temáticas são oferecidas antes que os estudantes visitem o museu. É mister saber o que explorar durante a visita, que não consiste em mera contemplação dos objetos expostos. Esses encontros consistem ainda em estratégia para criar aproximação dos graduandos com os alunos da escola estadual e tende a criar uma relação de confiança entre eles. O fato de convidar os estudantes da rede pública para transpor os muros da escola requer que o grupo seja coeso e tenha interação de maneira a permitir um bom diálogo. 
O deslocamento do espaço da escola ao museu é também outra potencialidade explorada junto a estudantes da rede pública e aos graduandos. É uma oportunidade de desenvolver uma aula peripatética ${ }^{4}$ quando o professor explora os espaços da cidade pela observação e análise dos estudantes. Durante essa aula, a interação com estudos literários e geográficos proporciona a exploração de aspectos físicos e morfológicos da cidade aliados a produções musicais e literárias ou a receitas culinárias, por exemplo.

\section{ANÁlise DOS RESUltados Do PROJETO}

O projeto demonstra a indissociabilidade entre Ensino, Pesquisa e Extensão, uma vez que permite aos estudantes da UEMG desenvolver habilidades práticas nos campos em que irão atuar profissionalmente, aliadas aos estudos teóricos oferecidos pela academia, oportunizando a participação em eventos acadêmicos, dinamizando o conhecimento produzido na/pela universidade.

Analisando, especificamente, as ações do projeto no ano de 2015, constatou-se que impactou os dois grupos envolvidos: os alunos do Ensino Fundamental e os da graduação.

IMPACTOS DO PROJETO ENTRE OS ALUNOS DO ENSINO FUNDAMENTAL

No primeiro contato, sentiu-se que os estudantes da rede estadual estavam desmotivados e desinteressados em participar das ações do projeto de extensão. A primeira oficina oferecida não despertou interesse dos alunos, havendo muita indisciplina e recusa em realizar as atividades. Nesse momento o papel da professora-coordenadora foi relevante para envolver os graduandos, que se assustaram com a indisciplina e a indiferença dos alunos. As reuniões do projeto foram fundamentais para reestruturar a forma de abordagem e trabalho com aqueles estudantes. Foram oferecidas leituras para os graduandos conhecerem experiências docentes com alunos indisciplinados e atitudes motivacionais.

Quando as ações foram revistas, a equipe percebeu que os alunos passaram a se interessar pelo projeto. Estrategicamente, partiu-se para a motivação 
dos estudantes oferecendo premiações (pequenos brindes com kits escolares ou bombons para os melhores trabalhos produzidos durante as oficinas). Optou-se também por eleger monitores naquela sala, oportunizando aos alunos indisciplinados exercer tal função. Tal estratégia visava valorizar aquele aluno que queria chamar a atenção, contudo se utilizava de atos hostis para com a equipe do projeto para conseguir êxito. Ao cooptar o aluno indisciplinado para ser monitor da turma dando a ele responsabilidades para gerir o grupo, constituiu-se uma oportunidade para que ele continuasse sendo protagonista naquele espaço, mas com ações positivas e reconhecidas perante a comunidade escolar.

Nas oficinas posteriores, percebeu-se que a estratégia funcionou e o grupo se interessou e se envolveu nas ações. $\mathrm{O}$ aluno indisciplinado sentiu-se valorizado pela atribuição que havia sido dada a ele - por exemplo, fiscalizar a limpeza da sala e a organização da sala de aula, colocando as mesas e carteiras em formato de semicírculo, antes de se iniciarem as oficinas.

Quando se realizou a terceira e última oficina, os alunos estavam receptivos, principalmente por se darem conta de terem sido a única turma de $9^{\circ}$ ano daquela escola a participar do projeto - como eles mesmos passaram a nomear, o "projeto do pessoal do museu".

Quando chegou o dia da visitação, os alunos esperavam ansiosos pela chegada da equipe e do ônibus escolar municipal, que fez o transporte ao museu e o retorno à escola. $\mathrm{O}$ envolvimento alcançou a interdisciplinaridade, haja vista a participação da professora de Língua Portuguesa, que acompanhou a visitação e ofereceu uma atividade aos alunos, aproveitando aquele contexto.

Nos percursos entre a escola e o museu e do museu de volta à escola notou-se que os alunos da E. E. João Belo de Oliveira absorveram as noções de patrimônio levantadas durante as oficinas. Fizeram apontamentos, observaram e reconheceram locais da cidade apresentados em fotografias, por ocasião das oficinas temáticas desenvolvidas anteriormente, em sala de aula.

Percebeu-se que a visitação representou para os alunos do $9^{\circ}$ ano um momento de aprendizado sobre Carangola. Possibilitou que ressignificassem suas noções sobre as relações com a cidade, despertando olhares e fazeres desconhecidos ou até mesmo relegados. Contudo, o que mais chamou a atenção da equipe do projeto foi a evolução no envolvimento dos estudantes durante todo 
o desenrolar das atividades de extensão. Quando se sentiram agentes no processo de construção do conhecimento e não meros espectadores, houve envolvimento, interesse e motivação. Esse impacto foi observado, na prática, pelos graduandos, que vivenciaram como o planejamento escolar é relevante no trabalho docente e como o ato de repensar a prática faz parte do cotidiano do educador.

\section{IMPACTOS DO PROJETO ENTRE OS GRADUANDOS} (ALUNA BOLSISTA E ALUNOS VOLUNTÁRIOS)

O contato com a sala de aula foi impactante para os graduandos. Na primeira oficina estes temeram a indisciplina dos alunos, que receberam a equipe com indiferença e, em alguns momentos, hostilidade.

Os graduandos representavam outsiders (Elias; Scotson, 2000) para aquele grupo. Esse contato inicial foi tema de inúmeras reuniões e estudos da equipe, em que se buscaram alternativas para que o trabalho fosse viável. São recorrentes o desinteresse de estudantes e os problemas enfrentados pelos professores por conta da indisciplina, aspecto que obsta os estudos e as leituras que os graduandos buscaram para elaborar atividades que despertassem a participação dos alunos e sua motivação. A disciplina tem papel preponderante, pois funciona como dispositivo a ser incentivado pelo professor com o objetivo de assegurar os limites das vontades individuais e o controle dos impulsos egoístas de seus alunos, garantindo assim a ordem, a continuidade e o respeito à vida social (Setton, 1999, p.77).

Discutiu-se como buscar a disciplina com um meio-termo no tocante à autoridade do professor, que, segundo Furter (1979), tem duas funções distintas: ensinar o aluno a se normatizar e levá-lo a usar sua liberdade.

As reuniões de estudos resultaram na criação de alternativas para aproximar os graduandos dos estudantes. Nas oficinas II e III percebeu-se maior interação e interesse dos alunos em participar das atividades oferecidas, o que demonstrou aos graduandos que as leituras e debates do espaço acadêmico encontraram sinergia com a realidade.

A estratégia de eleger monitores na sala, escolhendo para tal, estrategicamente, os alunos mais indisciplinados, foi positiva. Outra alternativa 
encontrada foi a premiação dos melhores trabalhos produzidos durante as oficinas, o que motivou os alunos.

A elaboração das atividades das oficinas possibilitou o contato com a realidade da sala de aula em uma escola pública e com o patrimônio material. Ademais, organizar uma visita guiada a um museu significou oportunidade de vislumbrar campos de trabalho, no caso da aluna do curso de Turismo, e o desenvolvimento de metodologias de trabalho, para a estudante voluntária do curso de História. Tal fato indica uma das potencialidades do projeto ao unir estudantes de História e Turismo e promover reflexões interdisciplinares.

Percebeu-se que o trabalho de extensão é ferramenta fundamental no desenvolvimento de habilidades dos graduandos. É notório a ganho de conhecimento advindo da experiência cotidiana, o que se pôde constatar na ocasião em que esses alunos compartilharam suas experiências com outros colegas, no âmbito da disciplina Orientação de Estágio I, ministrada pela Professora Coordenadora do Projeto, no quarto período do curso de História.

\section{CONSIDERAÇÕES FINAIS}

Os objetivos alcançados foram além do esperado, considerando-se que os graduandos vivenciaram, na sala de aula, a experiência cotidiana enfrentada pelos professores da Rede Pública Estadual. Experimentaram a necessidade de recriar planejamentos, rever ações e elaborar estratégias. Além da troca de conhecimento, vivenciaram por meio do trabalho extensionista o que faz o exercício da docência ser um desafio diário: envolver alunos e alunas no processo de construção do conhecimento.

No que se refere à visita guiada ao museu, representou oportunidade de reflexão sobre a formação profissional circunstanciada pela vivência daquele espaço como ambiente educador e campo de infinitas possibilidades de aprendizagem.

Como afirma Pereira (2007), o museu é ambiente educativo peculiar, e a experiência de uma visita monitorada engendra ações como o diálogo (sobre o que oferece, como se organiza, o que registra) e a percepção (leitura dos objetos).

A principal discussão levantada entre os alunos dos cursos de graduação foi a de se evitar que o museu se restrinja a um espaço turístico. A visitação a 
um museu vai além: é um ato de reflexão e análise sobre o que é aquele espaço, o conhecimento de diferentes culturas materiais, suas atividades, seus valores e suas relações com as pessoas. É um local de pensamento crítico, de indagações, de problematização de discursos e documentos.

As ações extensionistas possibilitaram aos dois cursos desenvolverem olhares diferentes para a visitação a museus e o ensino de História e ofereceram a experiência de formação profissional com estímulo à sensibilidade e à dialogicidade.

\section{REFERÊNCIAS}

ABREU, Regina Maria do R. M. Patrimônio cultural: tensões e disputas no contexto de uma nova ordem discursiva. In: LIMA FILHO, Manuel F.; BELTRÃO, Jane F.; ECKERT, Cornélia (Org.) Antropologia e patrimônio cultural: diálogos e desafios contemporâneos. Blumenau: Nova Letra, 2007. p.263-285.

ALENCAR, Vera Maria A. de. Museu-Educação: se faz caminho ao andar... Dissertação (Mestrado em Educação) - Pontifícia Universidade Católica do Rio de Janeiro (PUC-Rio). Rio de Janeiro, 1987. Disponível em: http://www2.dbd.puc-rio.br/ pergamum/teses/1987-ALENCAR_V_M_A.pdf; Acesso em: 20 maio 2015.

ALMEIDA, Adriana M. Desafios da relação museu-escola. Comunicação \& Educação, São Paulo, v.10, p.50-56, set./dez. 1997. Disponível em: http://www.revistas.usp. br/comueduc/article/view/36322/39042; Acesso em: 15 out. 2016.

BOSI, Ecléa. Memória e Sociedade: lembrança dos velhos. 2.ed. São Paulo: T. A. Queiroz; Edusp, 1987.

CANDAU, Vera Maria F. Ser professor/a hoje: novos confrontos entre saberes, culturas e práticas. Educação, Porto Alegre, v.37, n.1, p.33-41, jan./abr. 2014. Disponível em: http://revistaseletronicas.pucrs.br/ojs/index.php/faced/article/view/15003.

ELIAS, Norbert; SCOTSON, John L. Os estabelecidos e os outsiders: sociologia das relações de poder a partir de uma pequena comunidade. Trad. Vera Ribeiro. Rio de Janeiro: Jorge Zahar, 2000.

FREIRE, Paulo. Extensão ou comunicação. 13.ed. São Paulo: Paz e Terra, 2006. . Pedagogia da autonomia. São Paulo: Paz e Terra, 2011.

FURTER, Pierre. Educação e reflexão. 2.ed. Petrópolis: Vozes, 1979.

GADOTTI, Moacir. A escola na cidade que educa. Cadernos Cenpec, Nova série, [s.l.], v.1, n.1, maio 2006. Disponível em: http://cadernos.cenpec.org.br/cadernos/index. php/cadernos/article/view/160; Acesso em: 13 fev. 2015. 
GIMENO SACRISTÁN, J. O currículo: uma reflexão sobre a prática. Porto Alegre: Artmed, 2000.

GRUNBERG, Evelina. Educação Patrimonial: utilização dos bens culturais como recursos educacionais. Cadernos do CEOM, Chapecó, SC: Argos, n.12, p.159-180, 2000. Disponível em: https://bell.unochapeco.edu.br/revistas/index.php/rcc/article/view/2133; Acesso em: 27 set. 2015.

LOPES, Francisco R. Museu, ensino de história e sociedade de consumo. Trajetos, v.1, n.1, p.1-22, 2016. Disponível em: http://www.revistatrajetos.ufc.br/index.php/ Trajetos/article/view/43/20.

. Tentação do tempo: a máquina museológica na fabricação do passado. Fortaleza: Imprensa Universitária, 2016b.

MOLL, Jaqueline. Um paradigma contemporâneo para educação integral. Pátio - revista pedagógica, Porto Alegre, n.51, p.12-15, ago./set. 2009. Disponível em: http:// loja.grupoa.com.br/revista-patio/artigo/6376/um-paradigma-contemporaneo-para-a-educacao-integral.aspx; Acesso em: 26 set. 2015.

NORA. Pierre. Entre memória e história: a problemática dos lugares. Proj. História, São Paulo, v.10, dez. 1993. Disponível em: http://revistas.pucsp.br/index.php/revph/article/viewFile/12101/8763.

PAULA, João Antônio de. A extensão universitária: história, conceito e propostas. Interfaces, Belo Horizonte, v.1, n.1, p.5-23, jul./nov. 2013. Disponível em: https:// www.ufmg.br/proex/revistainterfaces/index.php/IREXT/article/view/5/pdf; Acesso em: 11 ago. 2016.

PEREIRA, Júnia S.; SIMAN, Lana Mara de C.; COSTA, Carina M.; NASCIMENTO, Silvania S. do. Escola e Museus: diálogos e práticas. Belo Horizonte: Secretaria de Estado de Cultura/Superintendência de Museus; Pontifícia Universidade Católica de Minas Gerais; Cefor, 2007.

SCIFONE, Simone. Educação e Patrimônio Cultural: reflexões sobre o tema. In: TOLENTINO, Átila B. (Org.) Educação Patrimonial: reflexões e práticas. João Pessoa: Superintendência do Iphan na Paraíba, 2012.

SETTON, Maria da Graça J. As transformações do final do século: ressignificando os conceitos de autoridade e autonomia. In: AQUINO, Julio G. (Org.) Autoridade e autonomia na escola: alternativas teóricas práticas. São Paulo: Summus, 1999. p.71-84.

SIMAN, Lana Mara de C. Práticas culturais e práticas escolares: aproximações a especificidades no ensino de história. História \& Ensino - revista do laboratório de ensino de história, Londrina, v.9, p.185-203, out. 2003.

TAVARES, Márcio. História, memória e identidade: como fazer um museu. Revista Autos \& Baixas, v.2, n.1, p.1-7, 2014. Disponível em: http://revistadigital.jfrs.jus. br/revista/index.php/revista_autos_e_baixas/article/view/58. 
VIÑAO FRAGO, Antonio. Do espaço escolar e da escola como lugar: propostas e questões. In: .; ESCOLANO, B. Currículo, espaço e subjetividade. Rio de Janeiro: DPA, 1998.

\section{NOTAS}

${ }^{1}$ Este trabalho conta com o Apoio do Edital PAEx 01/2016.

${ }^{2}$ Disponível em: http://portal.iphan.gov.br/portal/montarPaginaSecao.do?id=15481\&reto rno=paginaIphan; Acesso em: 14 dez. 2014.

${ }^{3}$ Fetichizar o patrimônio, segundo SCIFONI (2012) significa vê-lo como coisa em si mesmo, autônoma e independente dos processos que o constituíram. A fetichização serve assim aos propósitos de ocultar os sujeitos do trabalho e também as relações conflituosas e de dominação que envolvem sua produção, tornando-o objeto aparentemente neutro.

${ }^{4}$ Palavra de origem grega que significa "ambulante" ou "itinerante". Peripatéticos (ou "os que passeiam") eram discípulos de Aristóteles, em razão do hábito do filósofo de ensinar ao ar livre, caminhando enquanto lia, na Grécia Antiga.

Artigo recebido em 14 de novembro de 2016. Aprovado em 30 de janeiro de 2017. 